\title{
Calibration of High-Frequency Mechanical Impact Simulation Based on Drop Tests
}

\author{
Stefanos Gkatzogiannis, Peter Knoedel, and Thomas Ummenhofer
}

\author{
(Submitted October 17, 2019; in revised form January 13, 2020; published online May 4, 2020)
}

\begin{abstract}
A series of drop tests was implemented in the present study in order to allow the reproduction of a single impact identical to the high frequency mechanical impact (HFMI) under monitored conditions in the laboratory. Therewith, characterization of the investigated material's mechanical behavior by explicitly considering possible irregularities concerning the present deformation modes would be enabled. Main goal was the determination of the investigated material's dynamic yield stress for various strain rates inside the spectrum of interest, so that the Cowper-Symonds viscous material model would be calibrated for the subsequent HFMI simulation. The values of the dynamic yield stress extracted by the present drop tests show good agreement with other experimental methods regarding the investigated material S355. The introduction of the calibrated material behavior on the present drop tests in the finite element (FE) analysis of HFMI led to reduced preciseness though, in comparison with the FE analysis, which considered high strain rate tensile tests found in literature. A series of conclusions was drawn from both the experimental and numerical investigations, confirming most of the initial expectations. Further work is proposed, in order to clarify an incompatibility met during the numerical investigations.
\end{abstract}

Keywords FE analysis, high frequency mechanical impact, residual stresses, simulation, strain rate dependency

\section{Introduction}

High frequency mechanical impact (Ref 1) is an efficient mechanical post weld treatment that has been proven to increase significantly, even more than $100 \%$, the fatigue life of welded steel structures. The method, up to the moment, has been thoroughly investigated experimentally (Ref 2-10), etc. Based on these experimental investigations of the last decades, the method has been regulated (Ref 1,11$)$ for the most widely applied welded connections. Nevertheless, it is a common knowledge that the design codes in order to provide guidance for all relative practical applications and still lie on the safe side are usually quite conservative (see Ref 12 for instance).

On the contrary, modeling of HFMI with the finite element (FE) method would enable the investigation of various geometries and materials without the restricting cost of experimental investigations. At the same time, it would allow for the consideration of the HFMI effect in fracture mechanics

This article is an invited submission to JMEP selected from presentations at the Symposium "Joining and Related Technologies," belonging to the topic "Processing" at the European Congress and Exhibition on Advanced Materials and Processes (EUROMAT 2019), held September 1-5, 2019, in Stockholm, Sweden, and has been expanded from the original presentation.

Stefanos Gkatzogiannis, Peter Knoedel, and Thomas Ummenhofer, Karlsruhe Institute of Technology - KIT Steel \& Lightweight Structures - Research Center for Steel, Timber \& Masonry, OttoAmmann-Platz 1, 76131 Karsrluhe, Germany. Contact e-mail: stefanos.gkatzogiannis@kit.edu.

\begin{tabular}{|ll|}
\hline & \multicolumn{1}{|c|}{ List of Symbols } \\
\hline$e$ & Coefficient of restitution (-) \\
$V$ & Impact velocity (m/s) \\
$\sigma_{y}$ & Yield stress (Pa) \\
$m$ & Mass $(\mathrm{kg})$ \\
$R$ & Radius (m) \\
$\mathrm{E}$ & Young's modulus (Pa) \\
$v$ & Poisson's ratio (-) \\
$\sigma_{y}{ }^{\prime}$ & Dynamic yield stress (Pa) \\
$\rho$ & Density (kg/m $\left.{ }^{3}\right)$ \\
$u$ & Displacement (m) \\
$c$ & Damping (N s/m) \\
$f s(u)$ & Resisting force as a function of deformation $(\mathrm{N})$ \\
$p(t)$ & External transient loading (N) \\
$f$ & Frequency (Hz) \\
$\xi$ & Damping ratio (-) \\
$D, q$ & Coefficients of the Cower-Symonds model with no \\
$F_{\mathrm{f}}$ & physical meaning (-) \\
$\mathrm{M}$ & Friction force (N) \\
$H$ & Friction coefficient (-) \\
$\mathrm{SSE}$ & Tangent modulus (Pa) \\
$\mathrm{RMSE}$ & Rum of squared estimate of errors (-) \\
& Root-mean-square error (-) \\
\hline
\end{tabular}

analyses. Therewith, the positive influence of the treatment on each unique case could be estimated with preciseness, allowing for a less conservative design, whenever this is desired. Numerical investigations have been presented in the past as well (Ref 13-17), etc., neglecting in most cases though significant aspects of the simulation like the strain rate dependency of steel during the impact treatment or the preexistence of welding residual stresses (WRS) in the component. Engineering knowledge dictates that the above two factors would be crucial for the final residual stress (RS) state of the component, and based on the present state of the art 
both of them can be considered in a FE analysis. This was validated in two recent studies (Ref 18, 19), which have shown that the consideration of WRS and viscous material behavior can significantly increase the accuracy of HFMI simulation. Besides, simulation of the WRS has evolved rapidly in the last decades and most of the practical and special aspects of the method regarding metal arc welding have been covered in previous studies of the authors (Ref 20-25). Similarly, the viscoplastic nature of steel has as well been investigated experimentally (Ref 26, 27), etc., and suitable material models have been proposed over the years (Ref 28-30).

The viscoplastic material models are usually calibrated based on either high strain rate tensile tests like in Ref 13 or Split-Hopkinson tests (see Ref 26 for example). The dynamic yielding behavior of steel has mostly been considered identical same in both tension and compression, as for the static case. Nonetheless, a recent study by Cadoni et al. (Ref 26) has shown that significant deviation can be met for the two different types of loading. Initial expectations suggest that in the case of HFMI compressive behavior would be predominant. Of course, as the physical phenomenon under investigation is that of an impacting rigid spherical indenter on a semi-infinite plate, both compressive and tensile stresses are introduced. Still, underneath the contact area and on the boundaries of the introduced crater's rim, compressive stresses arise. The tensile stresses are introduced even deeper or wider as a counterbalance. This later consideration would arise questions regarding the use of material behavior, which was calibrated based on tensile tests, for the simulation of HFMI.

For this reason, a series of drop tests was carried out in the present study in order to reproduce a single impact similar to that of the HFMI device under monitored conditions. It was decided upon that the implemented experimental method should be straightforward and reproducible. Final goal was the calibration of a material model based on this experimental results and its implementation to a FE simulation of HFMI. FE commercial software LS-Dyna was applied for all subsequent numerical investigations (Ref 31).

\section{Methodology}

During the drop tests, the HFMI pin should carry out a free fall and impact on a specimen of the investigated material with a known velocity, carrying a known mass. Impact velocity during the experiment would be analytically calculated based on trivial physics. Analytical calculations based on the inelastic expansion of the Hertzian theory for impacts would enable the calculation of the dynamic yield strength based on measurements of the restitution coefficient. The plastic strain rate at yielding would be defined during a FE analysis of the impact. The obtained dynamic yield stress for the given strain rate would be at first validated based on the results of previous studies for the same material (see Ref 13, 27, etc.). The calibrated, strain rate-dependent material model would then be introduced to a FE simulation of HFMI. Comparison of this later FE model with measured profiles of residual stresses would act as a final validation step. A synopsis of the working steps is provided by the flowchart of Fig. 1.

\subsection{Experimental Setup}

The experimental setup, which was built for the present drop tests, is illustrated in Fig. 2(a). It consists of four columns that carry rails. An impact assembly consisting of a cross, with two wheels on each side so that excessive rotation would be excluded, a sinker and the HFMI pin on its bottom, would run along the rails and hit the tested component (Fig. 2b). A negligible rotation of $\pm 0.5^{\circ}$ was observed. The sinker was used for increasing the mass of the impact assembly. Between the wheels and the rails, a significant gap of $5 \mathrm{~mm}$ was held, so that the friction would be minimized and the impact assembly could be assumed to executing a free fall, without derailing though. A high-speed camera, able to catch $180 \mathrm{fps}$, was set at the same level with the upper surface of the tested component. Placing a ruler vertically, behind the tested specimen and knowing the distance between the camera's lens, the specimen surface and the ruler and their height from the ground level enabled the calculation of the rebound height with a preciseness of $\pm 1 \mathrm{~mm}$ and in extension of the restitution coefficient, based on trivial Euclidian geometry. Three different sinkers with mass of $3.06,9.42$ and $19.20 \mathrm{~kg}$ were manufactured. The rest of the impact assembly had a total mass of $9.24 \mathrm{~kg}$. The present experimental setup allows drop tests from up to maximum height of approximately $200 \mathrm{~cm}$ from the surface of the specimen.

\subsection{Analytical Estimation of Dynamic Yield Stress}

The coefficient of restitution $e$ of an impact was defined by Johnson (Ref 32) as follows:

$e^{2}=\frac{V^{\prime 2}}{V^{2}}$,

where $V$ and $V^{\prime}$ are the impact and rebound velocities, respectively. Johnson further proposed that this coefficient can be related to the dynamic yield of a semi-infinite plate, when it is hit by a sphere according to Eq 2,

$e \approx 3.8 \cdot\left(\frac{\sigma_{Y}^{\prime}}{E^{*}}\right)^{\frac{1}{2}} \cdot\left(\frac{\frac{1}{2} \cdot m_{\mathrm{sp}} \cdot V^{\prime 2}}{\sigma_{Y}^{\prime} \cdot R^{3}}\right)^{-\frac{1}{8}}$

where $E^{*}$ is given by the classical elastic Hertzian contact theory:

$\frac{1}{E^{*}}=\frac{1-v_{\text {sphere }}^{2}}{E_{\text {sphere }}}+\frac{1-v_{\text {plate }}^{2}}{E_{\text {plate }}}$.

Under the assumption of a rigid sphere, Eq 3 becomes

$\frac{1}{E^{*}}=\frac{1-v_{\text {plate }}^{2}}{E_{\text {plate }}}$.

Equation 2 was proposed for the case, when perfect spheres are investigated. The assumption regarding the intender's rigidity is based on the fact that it is manufactured by hard steel, which does not deform plastically during the drop tests or the HFMI treatment. In the present study, elastic deformation of the indenter is considered negligible in comparison with the plastic deformation of the treated surface. In the present experiments though, additional mass in comparison with Eq 3 is added to the impact assembly, on the bottom of which the HFMI pin is mounted. Hence and in order to exclude mass from the relationship, Eq 2 transforms as follows: 


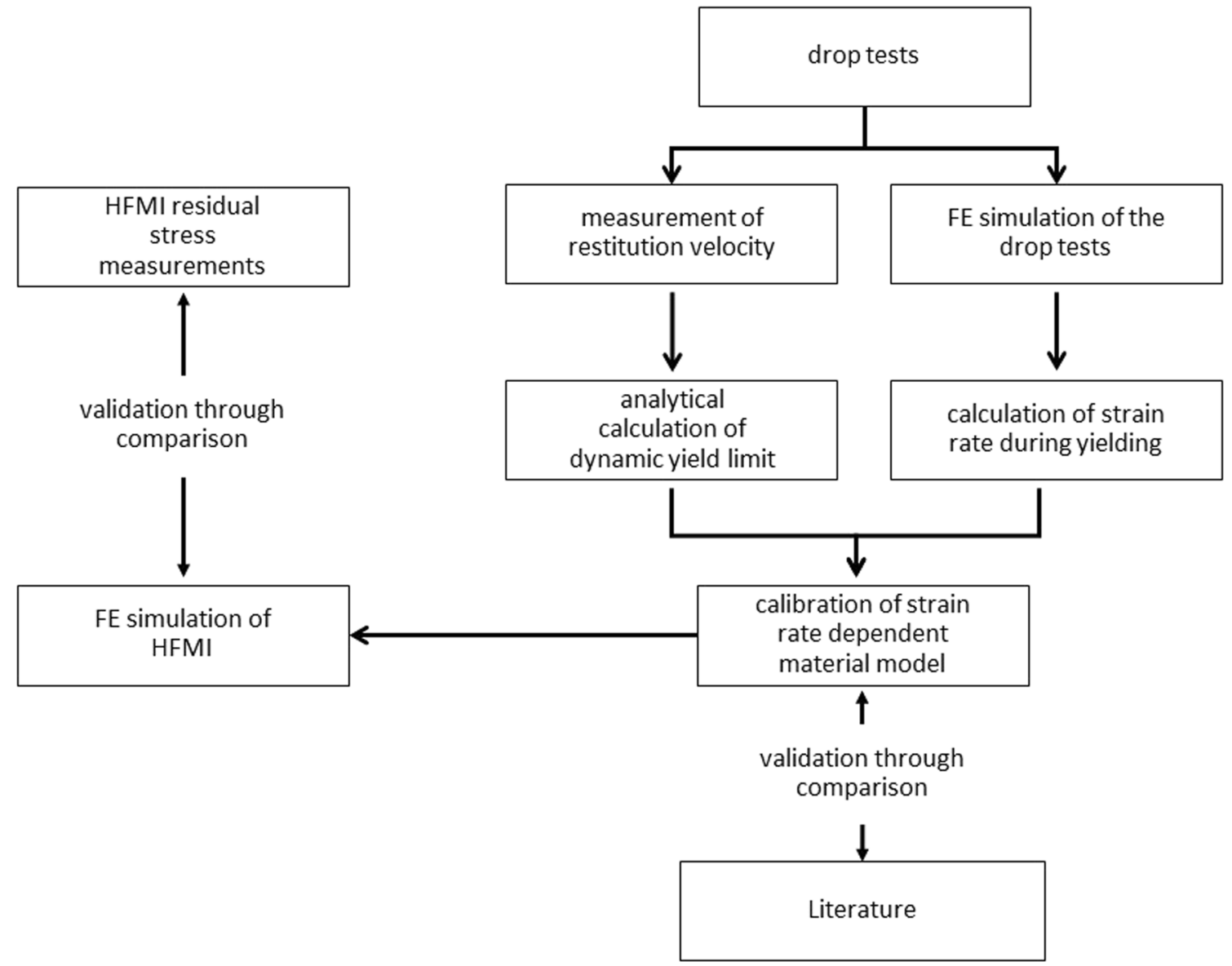

Fig. 1 Flowchart for the calibration of the strain rate dependent material behavior through the implementation of the drop tests

$e=3.46 \cdot \sigma_{\Upsilon}^{\frac{5}{8}} \cdot E^{*-\frac{1}{2}} \cdot V^{\prime-\frac{1}{4}} \cdot \rho^{-\frac{1}{8}}$.

Then, substituting $E^{*}$ from (4) and for $v=0.3$ and $\rho=7850 \mathrm{~kg} / \mathrm{m}^{3}$, Eq 5 becomes:

$\sigma_{\Upsilon}^{\prime}=0.90 \cdot e \cdot E^{\frac{1}{2}} \cdot V^{\prime \frac{1}{4}}$

\subsection{Numerical Investigations of Impacts}

2.3.1 Analysis Type. In cases of impact simulation, the deformation rate usually dictates if a full transient analysis has to be deployed, or the problem can be downgraded to a quasistatic analysis, whereby inertia effects are excluded. For the case of HFMI, in which strain rates between 200 and $400 \mathrm{~s}^{-1}$ are reported (Ref 13), a full dynamic analysis for nonlinear material behavior has to be considered. The known equation of motion governs this proposed analysis:

$m \cdot \ddot{u}+c \cdot \dot{u}+f S(u)=p(t)$.

Viscous damping models have been widely applied in dynamic analyses, and they have as well been applied in previous numerical investigations of HFMI (Ref 33) and similar cases (Ref 34, 35 etc.), whereby the damping coefficient $C$ of Eq 7 is given as follows: $c=2 \cdot f_{0} \cdot \xi \cdot m$.

$\xi$ was set equal to 0.5 in all cases, which was proven appropriate in similar, numerical investigations of shot peening (Ref 34).

2.3.2 Modeling Material Behavior. Bilinear material behavior is considered suitable for simulating the behavior of steel (Ref 21), and it has been applied in previous studies of the authors (Ref 33 for instance). Moreover, strain rate dependency of the steel's yield strength is expected to have a significant effect on the modeled WRS as it was stated above. Therefore, the Cowper-Symonds model (Ref 30) was applied for the present study.

$\dot{\varepsilon}_{\mathrm{pl}}=D \cdot\left(\frac{\sigma_{y}^{\prime}}{\sigma_{y}}-1\right)^{q}$.

2.3.3 Modeling of Contact Conditions. The friction between the pin and the treated surface has to be taken into consideration as well, as it leads to consumption of the kinetic energy of the pin. The Coulomb friction model was proposed in Ref 33 for simulating the friction between metallic parts. The model is described by Eq 10

$F_{\mathrm{f}}=\mu \cdot F_{N}$.

(Eq 10) 

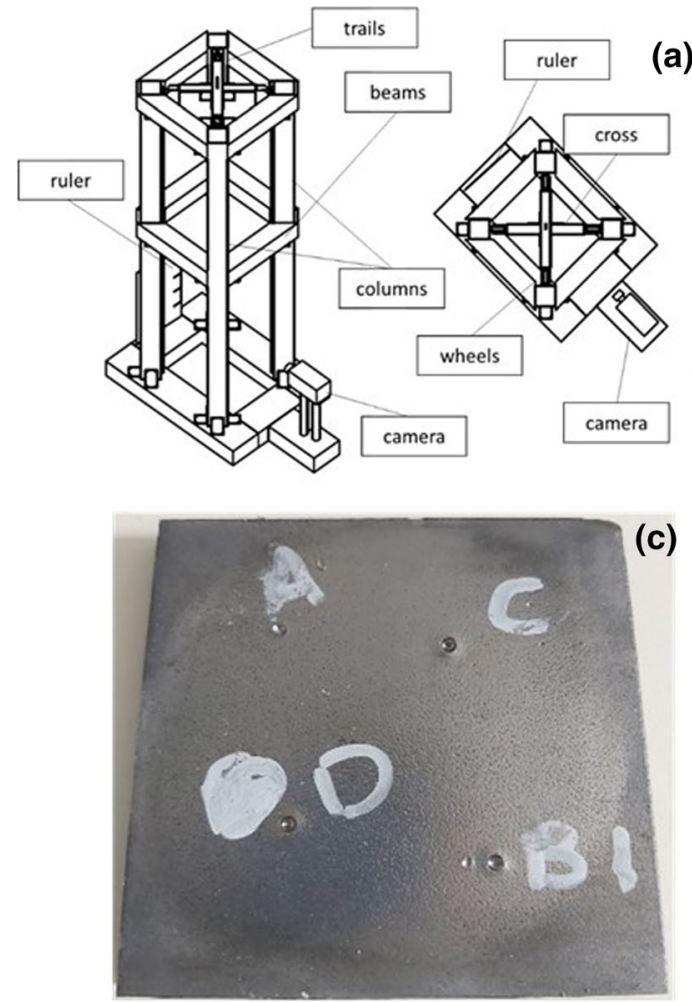

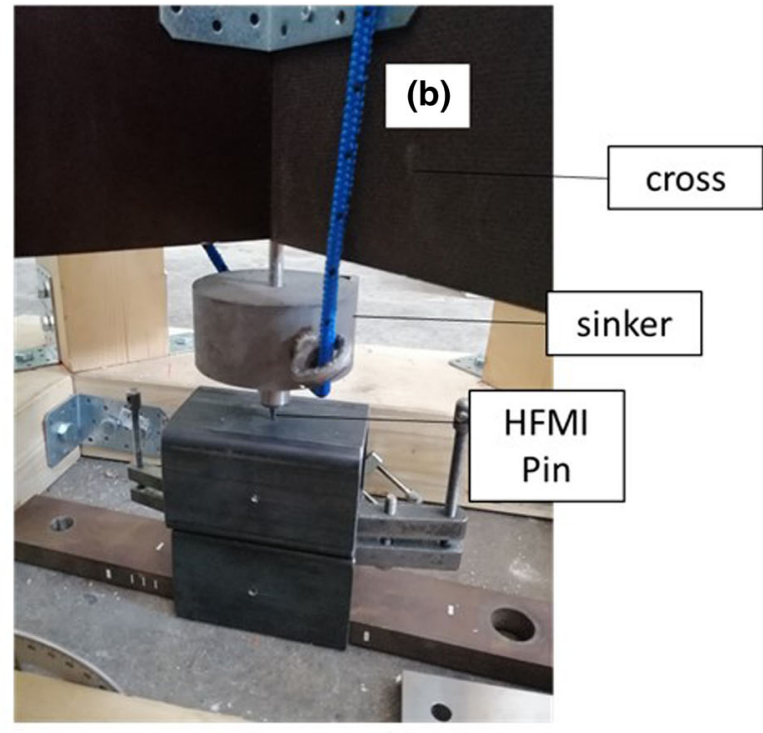

Fig. 2 (a) Experimental setup for the implementation of drop tests, (b) the impact assembly and (c) the investigated specimen, the craters from the 4 impacts can be seen

\section{Experimental Investigations}

A series of drop tests was carried out using the abovedescribed experimental setup. The plate of Fig. 2(c) made of the investigated hot rolled, structural steel S355J2+N (Ref 36) with dimensions $100 \mathrm{~mm} \times 100 \mathrm{~mm} \times 10 \mathrm{~mm}$ was tested. Potentially, residual stresses and strain hardening on the surface layer could have arisen during the rolling process. It was assumed that if initial residual stresses were present, they were relaxed due to cutting of the smaller tested plates. The upper surface of the specimen, where the impacts would take place, was grinded and polished prior to testing so that even small craters would become easily apparent. Therewith, the surface layer and in extension any local strain hardening effect were removed. Further processing of the specimens, for instance by annealing was excluded, as there is no such reference given for the specimens of Ref 15, the measurements of which are compared with the present simulation. Four impacts were carried out on the investigated specimen, in a sufficient horizontal distance from each other so that any interaction could be excluded. The lighter sinker of $3.06 \mathrm{~kg}$ was deployed, bringing the total mass of the impact assembly up to $12.3 \mathrm{~kg}$, as it was considered sufficient for the present goal. The drop tests were carried out from $22.1,47.4 \mathrm{~cm}$ and twice from $76.9 \mathrm{~cm}$. The drop height and the respective impact velocities for the four implemented impacts along with the yield stress, which was calculated analytically based on Eq 6, are given in Table 1.

It has to be underlined at this point that the reported typical strains of 200 to $400 \mathrm{~s}^{-1}$ are theoretical values proposed in Ref 15 without further proof. The strain rates can be extracted from a FE analysis, and they cannot be easily validated experimen-
Table 1 Calculation of the dynamic yield stress based on restitution coefficient

\begin{tabular}{lccccc}
\hline Impact & Drop height, $\mathbf{c m}$ & $\boldsymbol{V}, \mathbf{m} / \mathbf{s}$ & $\dot{\varepsilon}, \mathbf{s}^{-\mathbf{1}}$ & $\boldsymbol{V}^{\prime}, \mathbf{m} / \mathbf{s}$ & $\boldsymbol{\sigma}_{\boldsymbol{Y}}^{\prime}, \mathbf{N} / \mathbf{m m}^{\mathbf{2}}$ \\
\hline 3A & 22.1 & 2.082 & 6120 & 1.098 & 647 \\
3B & 47.4 & 2.991 & 6998 & 1.403 & 607 \\
3C & 76.9 & 3.882 & 8991 & 1.339 & 618 \\
3D & 76.9 & 3.882 & 8991 & 1.553 & 547 \\
\hline
\end{tabular}

tally. Numerical models could provide a valid estimation, if force- or velocity-based modeling of the pin's motion calibrated on the real HFMI device takes place and under the perquisite that the numerical model is very accurate. Therefore, these early values should be applied with cautiousness. Due to this uncertainty, the authors decided to test on higher strain rates in the present study, where the separation of the two populations responding to tensile and the compressive viscous behavior is becoming evident (see Fig. 6). In other words, the tests at higher strain rates lie on the safe side, when determination of the material behavior's nature under a certain deformation mode is the goal. In any case, previous studies of steel's viscosity (an overview is found in Ref 37) validate the exponential relationship between dynamic yield stress (dependent variable) and strain rate (independent variable), which should stand qualitatively in all cases. Therefore, tests at higher strain rates than the investigated ones can provide a sufficient calibration of the material model. 


\section{Numerical Investigations}

\subsection{Simulation of the Drop Tests Strain Rates with the FE Method}

As it was described earlier, a FE analysis of the drop tests was carried out in order to calculate the strain rate at yielding. The same methodology as for the case of HFMI simulation was applied, only that this time a single impact had to be modeled. Mesh density requirements had already been clarified in Ref 33 . Therewith, a mesh with average dimension of $0.1 \mathrm{~mm}$, but finer near the contact surface and coarsening away from it, was applied for the discretization of the component. The top layer of the component had elements with dimensions smaller than $0.075 \mathrm{~mm}$ in the contact area and in each direction. Double symmetry could be applied in this case, in order to further increase the computational time. Rigid body properties of the whole impact assembly, i.e., total mass, mass center and moments of inertia, were assigned to the pin in order to simulate precisely the impact force. The pin was modeled to hit the simulated component under a steady velocity, equal to the analytically calculated impact velocity for each drop test. Strain rate dependency was excluded from the simulation at this part in order to avoid an infinite loop, as the respective viscous material model would be the output of the drop tests. The average shear strain rate over the line $A B$ at Fig. 3(b) was considered, when the plastic spherical zone was introduced beneath the contact surface (Fig. 3a). The estimated strain rates are presented as well in Table 1 along with the respective results from the experimental part.

\subsection{Simulation of the HFMI}

The $20 \mathrm{~mm} \times 20 \mathrm{~mm} \times 10 \mathrm{~mm}$ component of structural steel S355, which is illustrated in Fig. 4 and it was modeled in Ref 33, was investigated as well in the present study. Once again, RS measurements, which were carried out in Ref 13 for an identical component, were applied as a validation base for the simulation. This time though, a force-based approach for simulating the vertical movement of the HFMI was applied. The force-based approach, vertical to its axis movement of the pin, was calibrated based on measurements of the impact velocity carried out in Ref 13 . Longitudinal movement of the pin remained displacement-based. In other words, the HFMI pin was accelerated toward the component with an arbitrary force until it reached its measured impact velocity prior to impact. It was then free of restraints on its vertical axis when contact with the component was initiated. After the end of contact and during the rebound, the pin would be horizontally displaced along the treatment line, and at the same time, the accelerating force would be reapplied until the impact speed would be reached again. The out-of-plane displacements and all rotations were restrained at all times. An overview of this modeling approach for the movement of the HFMI pin is illustrated in Fig. 5.

Three passes of $10 \mathrm{~mm}$ treatment length each, the first and last forwards and the second backwards, with an impact velocity of $4 \mathrm{~m} / \mathrm{s}( \pm 0.1 \mathrm{~m} / \mathrm{s})$ were modeled. The measurements of the RS were carried out on a specimen hammered with treatment velocity of $24 \mathrm{~cm} / \mathrm{min}$ for a reported impact frequency of $90 \mathrm{~Hz}$ (Ref 13), which corresponds to an average step of $0.04 \mathrm{~mm}$ between consecutive impacts. Nevertheless, in order to maintain a balance between computational time and
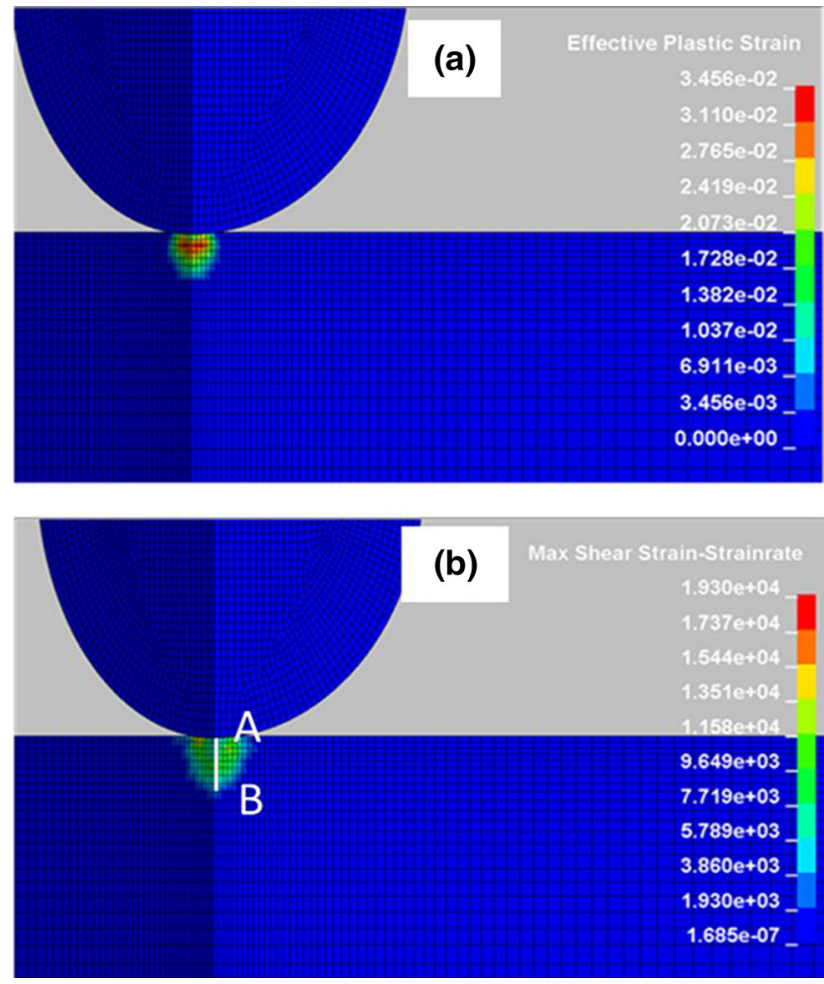

Fig. 3 Introduction of the plastic strain spherical zone underneath the impact surface-(a) Von Mises strain rate and (b) maximum shear strain rate

preciseness, a longitudinal displacement of $0.2 \mathrm{~mm}$ between consecutive impacts was applied instead. Previous analyses have shown that such a simplification does not compromise the preciseness of the simulation (Ref 13, 16, 33).

Finally, the consideration of a force-based modeling of the HFMI pin's movement lifts the restrictions regarding the application of strain rate-dependent material model, which were previously discussed in Ref 33, when a displacement-based approach is applied instead. During such a displacement-based approach, the pin is forced into the treated material similarly to a punching process with a pre-described, steady-velocity displacement, which cannot simulate the deformation rate realistically. Assumptions of a sinusoidal, vertical movement of the pin could be made but validation measurements would be very difficult in this case. Therefore, this method is appropriate for non-viscous material behavior only. For the present case of force-based modeling though, measurements of the contact force and a correlation with an impact velocity were already carried out in Ref 13. Therewith, a consideration of viscosity is possible and the Cowper-Symonds model (Eq 9) was applied. It was calibrated twice, in tension and in compression, respectively. This was decided, in order to check the initial, above-stated assumption that compressive deformation mode and the respective strain rate dependency would be predominant in this simulation. For the former case, experimental results of high strain rate tensile test from Ref 13 were applied, while for the latter the data from the present drop tests were considered along with the experimental compressive results from Ref 26, so that the statistical sample would be increased (Table 1).

Calibration of the Cowper-Symonds model was carried out with MATLAB statistic toolbox (Ref 38 ). The results of the 


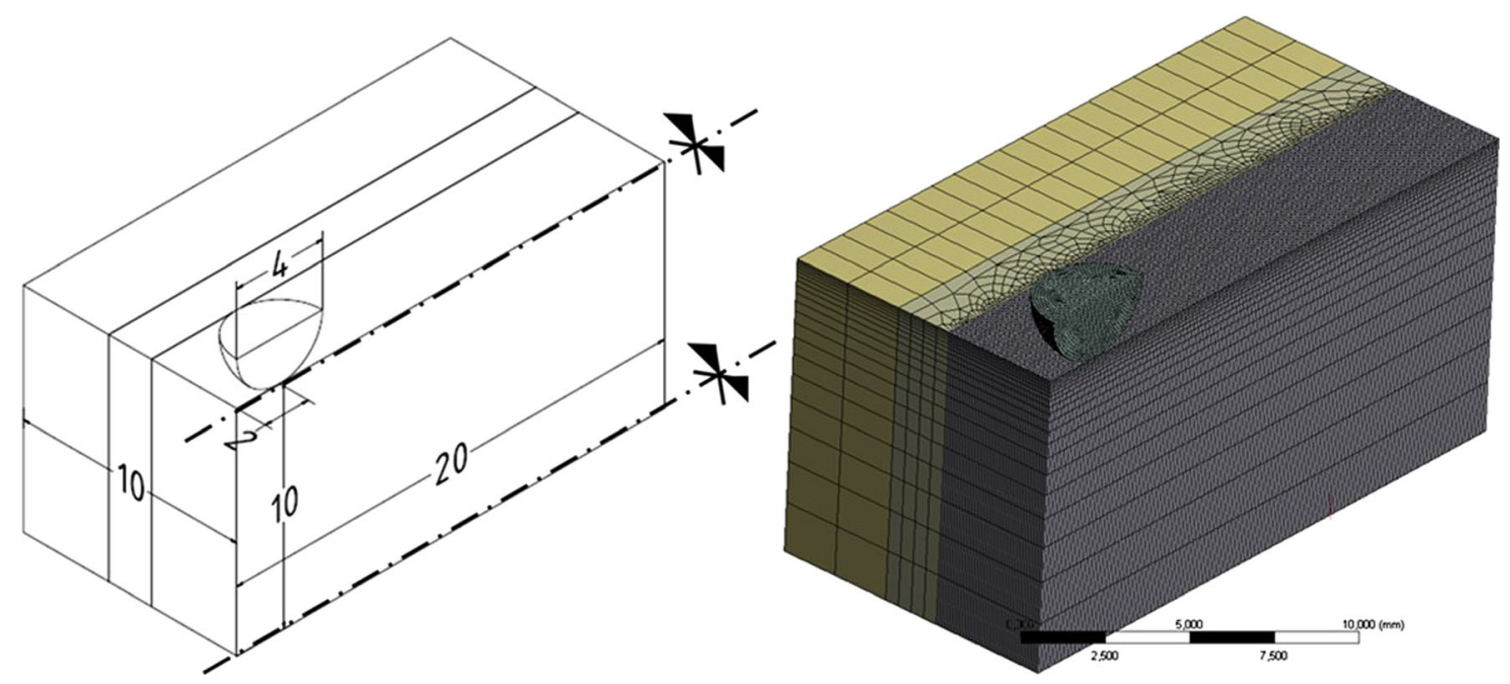

Fig. 4 Investigated specimen of parent material with dimensions $20 \mathrm{~mm} \times 20 \mathrm{~mm} \times 10 \mathrm{~mm}$ with a symmetry plane at the middle and the applied mesh - a HFMI pin with diameter of $4 \mathrm{~mm}$ is considered

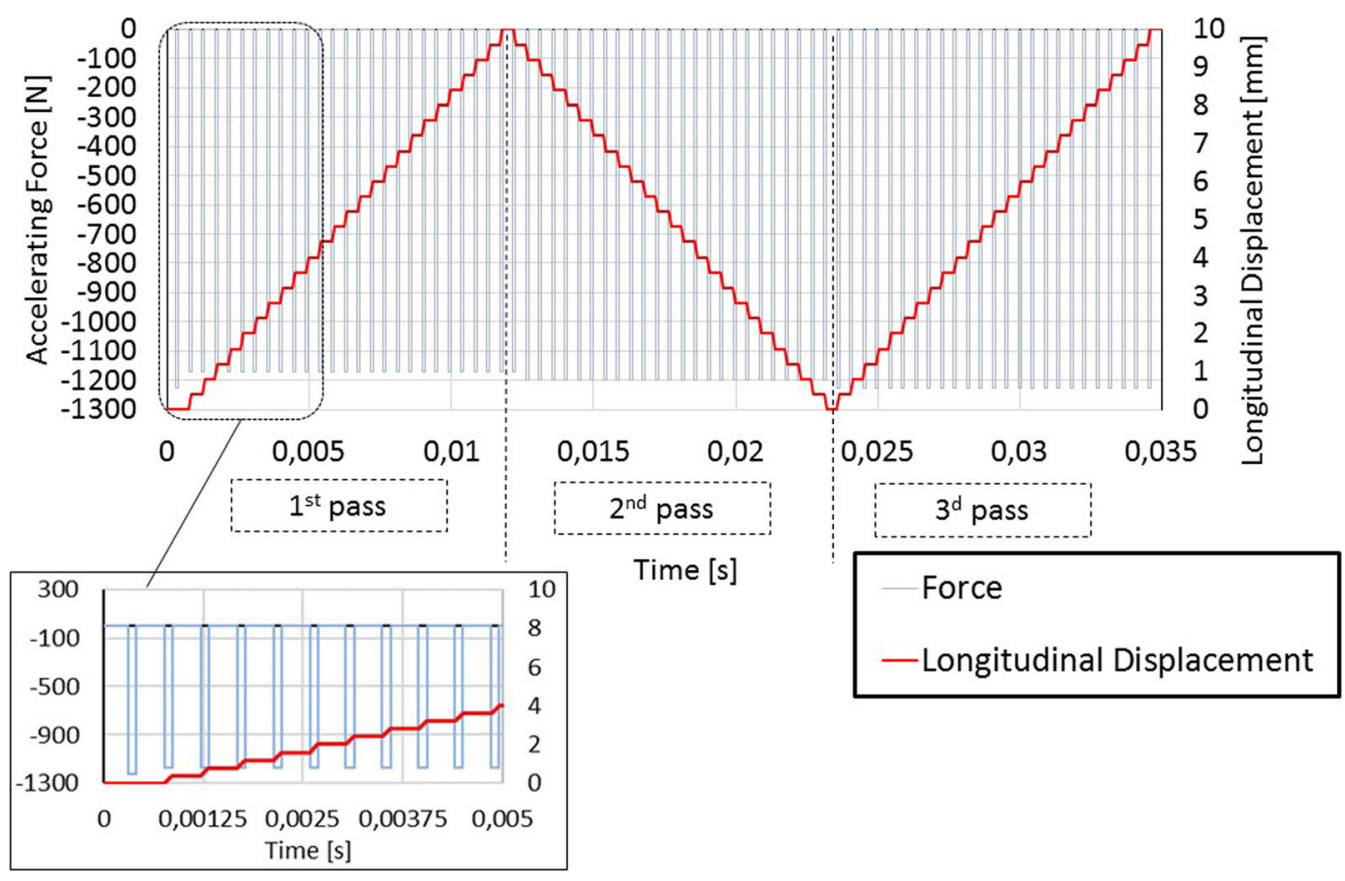

Fig. 5 Diagram of accelerating force and longitudinal displacement of the pin over time, for 3 consecutive passes during a force-based simulation

correlation and the indices for the quality of the fit are presented in Table 2. The two simulations including viscous material behavior were compared with the classical strain rate independent, elastic-plastic case. Bilinear material behavior with kinematic or mixed hardening was applied in all cases, and its calibration for the static case was based on static tensile tests from another ongoing research project. Due to overlap of consecutive impacts during the HFMI treatment, reversals of plastic deformation take place. Material areas initially under tension are subsequently deformed under compression and vice versa. Therefore, the hardening behavior of material could be predominant for the accuracy of the simulated RS. The quantitative influence of altered hardening behavior has been already investigated and presented in previous studies (see Ref 15 for instance), and it was suggested that the consideration of a mixed hardening behavior provides better results than in the case of kinematic hardening. Nonetheless, under the present modeling approach, switching from kinematic to a mixed hardening behavior did not produce such a significant deviation of the simulated RS, and therefore, the respective results are omitted for the sake of space. Kinematic hardening was applied in all the presented cases. 


\section{Results and Discussion}

The dynamic yield stress was extracted from the present drop tests for various train rates and estimated based on the above-presented analytical and numerical calculations. This was compared with respective results from previous studies for the same material, S355, in Fig. 6. Results of the present investigations tend to create one separate population, along with the compressive results from Ref 26. This group of values seems to have lower strain rate sensitivity than the rest of the results, which were extracted with high strain rate tensile testing. Therewith, the previously stated assumption that during the single spherical indentation the compressive viscous behavior is predominant is further supported. Moreover, for the last two drop tests and for same impact velocity and strain rate, yield stresses of 618 and $547 \mathrm{MPa}$, respectively, are calculated. This difference could be at first considered significant. Nonetheless, it is becoming evident from Fig. 6 that the tests for the estimation of the dynamic yield stress exhibit in general a severe scatter band. In some cases, the difference is even up to $15 \%$ for tests at the same strain rate. Hence, the above deviation is considered acceptable for the present tests.

The transverse and longitudinal HFMI RS profiles in depth direction, modeled with two rate independent and two viscous material models, are presented in Fig. 7 and 8, respectively, along with the measured RS profiles found in Ref 13. In the former case, all three material models produce RS profiles qualitatively similar with each other and with the measured ones. In all cases, the peak RS lie in a depth of approximately $0.5-0.8 \mathrm{~mm}$. FE simulation seems to overestimate this transverse RS peak though, especially in the case of the strain ratedependent material modeling. Nevertheless, this discrepancy can be considered negligible and the agreement between measured and simulated RS profiles is as well quantitatively very good for the rest of the measurement locations. In the case of the longitudinal RS though, the strain rate-independent model is proven insufficient to simulate even qualitatively the measured RS profile. It significantly underestimates RS near the surface. On the contrary, the two viscous models simulated the measured profiles both qualitatively and quantitatively with high preciseness. This discrepancy between the strain rateindependent and strain rate-dependent models is expected. The area and the respective FE elements beneath and near the contact surface are those who are strained under the highest rate. Therefore, they exhibit the highest yield stress, and for this reason, the $\mathrm{RS}$ in shallower depths are going to be higher than in deeper locations. This effect cannot be caught by a simulation, where strain rate dependency is neglected.

Nonetheless, a discrepancy is met when the two models are compared; against initial expectations, the FE model calibrated with the tensile test results provides better agreement, while the

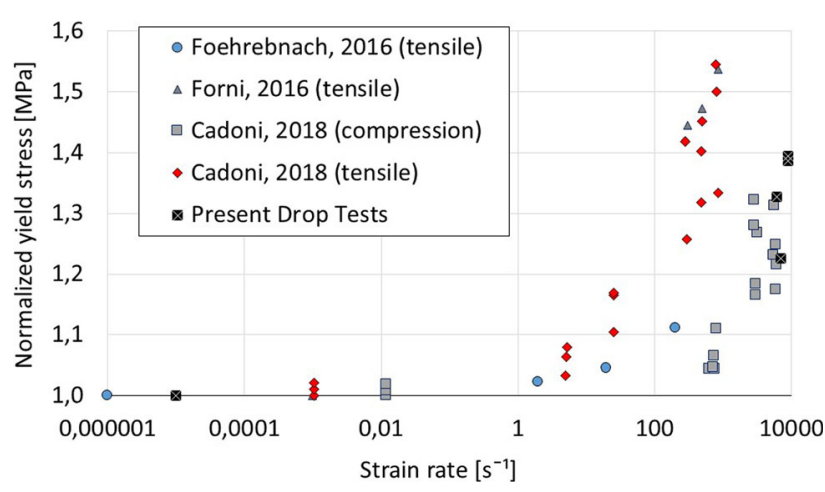

Fig. 6 The dynamic yield strength of S355 as a function of the strain rate results from present drop tests and previous studies by Foehrenbach et al. (Ref 12), Cadoni et al. (Ref 21) and Forni et al. (Ref 22)

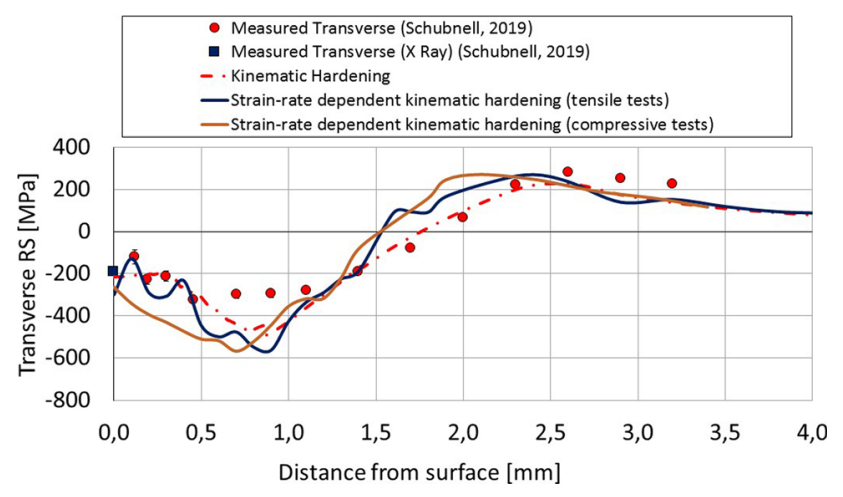

Fig. 7 Simulated and measured transverse RS-component of parent material S355

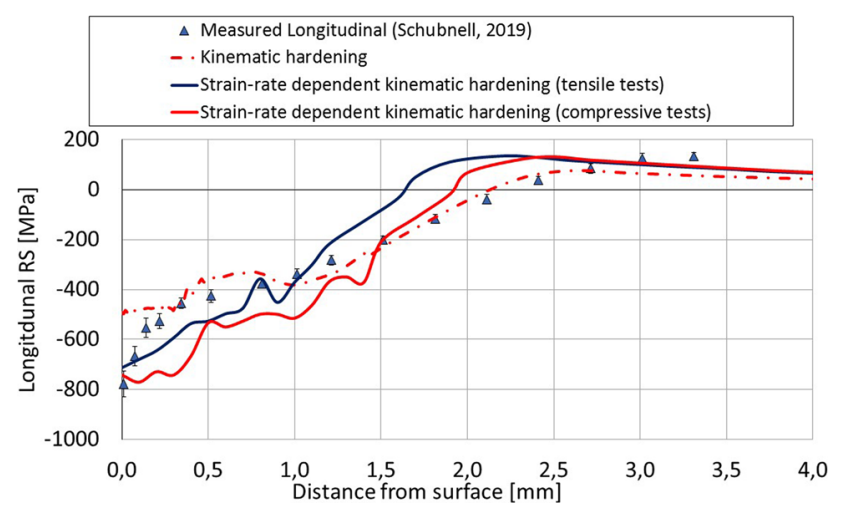

Fig. 8 Simulated and measured longitudinal RS-component of parent material S355

Table 2 Calibration of the bilinear material behavior and the Cowper-Symonds model

\begin{tabular}{|c|c|c|c|c|c|c|c|c|c|}
\hline \multirow[b]{2}{*}{ Model } & \multirow[b]{2}{*}{$\begin{array}{c}\sigma_{y} \\
\mathbf{M P a}\end{array}$} & \multirow[b]{2}{*}{$\begin{array}{c}H, \\
\text { GPa }\end{array}$} & \multirow[b]{2}{*}{$D,-$} & \multirow[b]{2}{*}{$\begin{array}{l}q \\
-\end{array}$} & \multirow[b]{2}{*}{ Calibrated based on } & \multicolumn{4}{|c|}{ Goodness of fit } \\
\hline & & & & & & $\begin{array}{c}\text { SSE, } \\
-\end{array}$ & $\begin{array}{c}\boldsymbol{R} \text {-square } \\
-\end{array}$ & $\begin{array}{c}\text { Adjusted } R \text { - } \\
\text { square, - }\end{array}$ & $\begin{array}{c}\text { RMSE, } \\
-\end{array}$ \\
\hline Tensile & 450 & 0.9 & 353,500 & 5 & Foehrenbach et al. (Ref 12) & 3584 & 0.8197 & 0.8197 & 34.56 \\
\hline Compressive & 450 & 0.9 & 613,500 & 4 & Drop Tests and Cadoni et al. $(\operatorname{Ref} 21)$ & 21,620 & 0.7126 & 0.7126 & 29.15 \\
\hline
\end{tabular}


compressive one tends to overestimate the magnitude of the introduced RS. This does not necessarily overthrow the assumption regarding the predominance of compressive viscous behavior, but it can be attributed to various factors. For instance, previous studies have shown that even different batches from the same material can exhibit quite different strain rate sensitivity due to differences in microstructure, such as the grain size, as it is discussed in Ref 25 . In the present case, both the measurements and the tensile experimental data are adopted from Ref 13, and they refer to the same batch of S355. This could explain the better agreement of the tensile viscous model in comparison with that calibrated on the present drop tests. Furthermore, the results of the present single impact drop tests indeed validated the assumption about the predominance of compressive behavior. Still, the HFMI treatment consists of multiple consecutive overlapping, but not coinciding impacts, which introduce significant reversals of plasticity. In other words, material areas, which were under tension during the first impact, are deforming under compression in the next one and vice versa. Thus, this predominance of the compressive behavior could be reduced or eliminated. As it is becoming evident from Fig. 6, the strain rate-dependent material testing exhibits significant scatter. It is possible, that even a larger sample would be needed for safer conclusions. Additional drop tests and HFMI residual stress measurements on specimens from the same batch and for a wider range of strain rates are encouraged in future work. Finally, the present assumption that the intender's elastic deformation can be neglected should be validated as well. Investigating the influence of the rigidity assumption on the simulated strain rates or RS during simulations of the drop tests or the HFMI treatment, respectively, is proposed as well for future investigations.

\section{Summary and Conclusions}

To summarize, drop tests combined with FE analysis and analytical calculations enabled the estimation of the dynamic yield stress of the structural steel S355. Based upon, the material model Cowper-Symonds was fitted with satisfying goodness. This strain rate-dependent model was implemented in a HFMI simulation model. The following major conclusions were drawn:

- Strain rate dependency is according to initial expectations predominant for the accurate modeling of the HFMI RS profiles.

- Force-based modeling of the HFMI pin's vertical movement is confirmed to be appropriate for simulations considering strain rate dependency.

- Dynamic yield stress estimated with the drop tests shows that for a single HFMI impact, lies closer to the ones extracted with compressive high strain rate testing, confirming as well initial expectations about the predominance of compressive viscosity during a single impact.

- In contrast to the previous argument, FE analysis of HFMI considering the tensile viscous material model provided better agreement with the respective measurements. Assumptions for this incompatibility were stated, and appropriate future investigations were proposed.

\section{Acknowledgments}

Open Access funding provided by Projekt DEAL. The present study was carried out in the framework of Gkatzogiannis' Doctoral Dissertation (Ref 39).

\section{Open Access}

This article is licensed under a Creative Commons Attribution 4.0 International License, which permits use, sharing, adaptation, distribution and reproduction in any medium or format, as long as you give appropriate credit to the original author(s) and the source, provide a link to the Creative Commons licence, and indicate if changes were made. The images or other third party material in this article are included in the article's Creative Commons licence, unless indicated otherwise in a credit line to the material. If material is not included in the article's Creative Commons licence and your intended use is not permitted by statutory regulation or exceeds the permitted use, you will need to obtain permission directly from the copyright holder. To view a copy of this licence, visit http://creativecommons.org/licenses/by/4.0/.

\section{References}

1. G.B. Marquis and Z. Barsoum, IIW Recommendations for the HFMI, Treatment-For Improving the Fatigue Strength of Welded Joints, 1st ed., Springer Singapore (IIW Collection), Singapore, 2016

2. T. Ummenhofer, REFRESH: Lebensdauerverlängerung bestehender und neuer geschweißter Stahlkonstruktionen, Abschlussbericht D 761, KIT Stahl- und Leichtbau, Versuchsanstalt für Stahl, Holz und Steine, Karlsruhe, 2009

3. T. Ummenhofer, I. Weich, and T. Nitschke-Pagel, Lebens- und Restlebensdauerverlängerung geschweißter Windenergieanlagentürme und anderer Stahlkonstruktionen durch Schweißnahtnachbehandlung, Stahlbau, 2005, 74(6), p 412-422

4. T. Ummenhofer, I. Engelhardt, P. Knoedel, S. Gkatzogiannis, J. Weinert, D. Loeschner, Erhöhung der Ermüdungsfestigkeit von Offshore-Windenergieanlagen durch Schweißnahtnachbehandlung unter Berücksichtigung des Korrosionseinflusses, Schlussbericht. Forschungsvorhaben IGF-Nr.: 18.457N/DVS-Nr.: 09.069, KIT Stahl- und Leichtbau, Versuchsanstalt für Stahl, Holz und Steine und Hochschule für angewandte Wissenschaften, Labor für Stahl- und Leichtmetallbau, Karlsruhe und München, 2017

5. J. Weinert, S. Gkatzogiannis, I. Engelhardt, P. Knoedel, T. Ummenhofer, Application of High Frequency Mechanical Impact Treatment to Improve the Fatigue Strength of Welded Joints in Corrosive Environment, IIW-XIII-2781-19, 72nd IIW Annual Assembly and International Conference 2019, Bratislava 7-12 July, 2019

6. H.C. Yildirim and G.B. Marquis, Overview of Fatigue Data for High Frequency Mechanical Impact Treated Welded Joints, Weld. World, 2013, 56(7-8), p 82-96

7. E. Mikkola and H. Remes, Allowable Stress in High-Frequency Mechanical Impact (HFMI)-Treated Joints subjected to Variable Amplitude Loading, Weld. World, 2017, 61(1), p 125-138

8. G. Marquis and Z. Barsoum, Fatigue Strength Improvement of Steel Structures by High-Frequency Mechanical Impact: Proposed Procedures and Quality Assurance Guidelines, Weld. World, 2014, 58(1), p $19-28$

9. H.C. Yildirim and G.B. Marquis, A Round Robin Study of High Frequency Mechanical Impact (HFMI)-Treated Welded Joints Subjected to Variable Loading, Weld. World, 2013, 57(3), p 437-447

10. K. Ghahremani, M. Safa, J. Yeung, S. Walbridge, C. Haas, and S. Dubois, Quality Assurance for High-Frequency Mechanical Impact (HFMI) Treatment of Welds using Handled 3D Laser Scanning Technology, Weld. World, 2015, 59(3), p 391-400

11. DASt—Richtlinie 026; Ermüdungsverbesserung bei Andwendung höherfrequenter Hämmerverfahren, 2019 
12. P. Knoedel, T. Ummenhofer, Accidental Torsion with Industrial Buildings-Over-Conservative Rules in EC8, The 14th Nordic Steel Construction Conference, Copenhagen 18-20 September 2019, CE/ Papers 3 (3-4), pp. 499-504, 2019

13. K.L. Yuan and Y. Sumi, Modelling of Ultrasonic Impact Treatment (UIT) of Welded Joints and Its Effect on Fatigue Strength, Frattura ed Integrità Strutturale, 2015, 34, p 476-486

14. P. Schaumann and C. Keindorf, Numerische Schweißsimulation gekoppelt mit einem anschließenden Hämmerprozess und integrierten lokalen Ermüdungsberechnungen, Stahlbau, 2010, 79(1), p 34-45

15. J. Foehrenbach, V. Hardenacke, and M. Farajian, High Frequency Mechanical Impact Treatment (HFMI) for the Fatigue Improvement: Numerical and Experimental Investigations to describe the Condition in the Surface Layer, Weld. World, 2016, 60(4), p 749-755

16. D. Simunek, M. Leitner, M. Stoschka, Numerical Simulation Loop to Investigate the Local Fatigue Behaviour of Welded and HFMI-Treated Joints, IIW Document XIII-WG2-136-13

17. J. Zheng, A. Ince, L. Tang, Modelling and Simulation of Weld Residual Stresses and Ultrasonic Impact Treatment of Welded Joints, 7th International Conference on Fatigue Design, Fatigue Design 2017, Senlis 29-30 November 2017, Procedia Engineering 213, pp. 36-47, 2018

18. C. Ernould, J. Schubnelll, M. Farajian, A. Maciolek, D. Simunek, M Leitner, and M. Stotschka, Applications of Different Simulation Approaches to Numerically Optimize High-Frequency Mechanical Impact (HFMI) Post-Treatment Process, Weld. World, 2019, 63(3), p 725-738

19. M. Leitner, D. Simunek, S.F. Shah, and M. Stotschka, Numerical Fatigue Assessment of Welded and HFMI-Treated Joints by Notch Stress/Strain and Fracture Mechanical Approaches, Adv. Eng. Softw., 2018, 120, p 96-106

20. P. Knoedel, S. Gkatzogiannis, and T. Ummenhofer, FE Simulation of Residual Welding Stresses: Aluminum and Steel Structural Components, Key Eng. Mater., 2016, 710, p 268-274

21. P. Knoedel, S. Gkatzogiannis, and T. Ummenhofer, Practical Aspects of Welding Residual Stress Simulation, J. Constr. Steel Res., 2017, 132, p 83-96

22. S. Gkatzogiannis, P. Knoedel, T. Ummenhofer, FE Welding Residual Stress Simulation-Influence of Boundary Conditions and Material Models, Proceedings of EUROSTEEL 2017, Copenhagen 13-15 September 2017, ce/papers 1, Ernst \& Sohn Berlin, 2017

23. S. Gkatzogiannis, P. Knoedel, T. Ummenhofer, Influence of Welding Parameters on the Welding Residual Stresses, Proceedings of the VII International Conference on Coupled Problems in Science and Engineering, Rhodes 12-14 June 2017, pp. 767-778, 2017

24. S. Gkatzogiannis, P. Knoedel, T. Ummenhofer, Reviewing the Influence of Welding Setup on FE-Simulated Welding Residual Stresses, Proceedings of the 10th European Conference on Residual Stresses-ECRS10, Leuven 11-14 September 2018, published in Materials Research Proceedings 6, pp. 197-202, 2018
25. S. Gkatzogiannis, P. Knoedel, and T. Ummenhofer, Strain Rate Dependency of Simulated Welding Residual Stresses, J. Mater. Eng. Perform., 2017, 27(10), p 5079-5085

26. E. Cadoni, D. Forni, R. Gieleta, and L. Kruszka, Tensile and Compressive Behaviour of S355 Mild Steel in a Wide Range of Strain Rates, Eur. Phys. J. Spec. Top., 2018, 227, p 29-43

27. D. Forni, B. Chiaia, and E. Cadoni, High Strain Rate Response of S355 at High Temperatures, Mater. Des., 2016, 94, p 467-478

28. G.R. Johnson, W.H. Cook, A Constitutive Model and Data for Metals Subjected to Larger Strains, High Strain Rates and High Temperatures, Proceedings of the 7th International Symposium on Ballistics, the Hague 19-21 April 1983, pp. 541-547, 1983

29. P. Perzyna, Fundamental Problems in Viscoplasticity, Adv. Appl. Mech., 1966, 9, p 243-377

30. G.R. Cowper, P.S. Symonds, Strain Hardening and Strain Rate Effects in the Impact Loading of Cantilever Beams, Report No. 28, Brown University Division of Applied Mathematics September 1957

31. LS-DYNA, Theory Manual, Livermore Software Technology Corporation (LSTC), Livermore California 2016

32. K.L. Johnson, Contact Mechanics, 1st ed., Cambridge University Press, Cambridge, 1985

33. S. Gkatzogiannis, P. Knoedel, T. Ummenhofer, FE Simulation of High Frequency Mechanical Impact (HFMI) Treatment-First Results, Proceeding of NSCC 2019, The 14th Nordic Steel Construction Conference, Copenhagen 18-20 September 2019, ce/papers 3 (3-4), pp. 797-802, Ernst \& Sohn Berlin, 2019

34. T. Kim, H. Lee, H.C. Hyun, and S. Jung, A Simple But Effective FE Model with Plastic Shot for Evaluation of Peening Residual Stress and Its Experimental Validation, Sci. Eng. A, 2011, 528, p 5945-5954

35. T. Kim, H. Lee, S. Jung, and J.H. Lee, A 3D FE Model with Plastic Shot for Evaluation of Equi-Biaxial Peening Residual Stress Due to Multi-Impacts, Surf. Coat. Technol., 2012, 206, p 3125-3136

36. DIN EN 10025-2:2018-07, Hot Rolled Products of structural Steels-Part 2: Technical Delivery Conditions for Non-alloy Structural Steels

37. P.S. Symonds, Survey of Methods of Analysis for Plastic Deformation of Structures under Dynamic Loading, Department of the Navy Office of Naval Research Contract Nonr 3248(01)(X), Naval Ship Research and Development Centre, 1967

38. MATLAB and Statistics Toolbox Release R2015a, The MathWorks, Natick, Massachusetts, USA, 2015

39. S. Gkatzogiannis, Finite Element Simulation of Residual Stresses from Welding and High Frequency Hammer Peening, Doctoral Dissertation, Karlsruhe Institute of Technology, Steel- and Lightweight Structures, to be submitted in 2019

Publisher's Note Springer Nature remains neutral with regard to jurisdictional claims in published maps and institutional affiliations. 